\title{
OPTIMASI ALAT PRAKTIKUM TERMODINAMIKA HUKUM CHARLES GAY-LUSSAC UNTUK MAHASISWA REKAYASA POLITEKNIK NEGERI BANDUNG
}

\author{
Ratu Fenny Muldiani ${ }^{1}$, Kunlestiowati Hadiningrum ${ }^{2}$ \\ Politeknik Negeri Bandung
}

Email: ratu.fenny@polban.ac.id ${ }^{1}$, kunlestiowati@polban.ac.id ${ }^{2}$

\begin{abstract}
Based on the syllabus of thermodynamics course in several Engineering Study Programs at Politeknik Negeri Bandung, it shows a very high need for Applied Physics on the subject of Thermodynamics as a prerequisite course. To be able to understand the concept of thermodynamics through laboratory activities, in this research the design and optimization of the Charles GayLussac's Law device was carried out, the measurement results were confirmed by calculation data using literature. Charles's law states that at fixed pressure, the volume of ideal gas with a certain mass is directly proportional to its temperature and Gay-Lussac's Law states that if the gas in a closed container is kept constant then the gas pressure is directly proportional to its absolute temperature. The results of the design of the Charles's law experiment device, on $P=925 \mathrm{mbar}$ and $T=298 \mathrm{~K}$, obtained the average pressure of the trial results is 1043 mbar. The test results from the setting of the device show the average coefficient of determination $\left(R^{2}\right)=0.9969$, meaning that the effect of temperature is strong on changes in volume at a fixed pressure. In the design of the Gay-Lussac's law experiment, at $925 \mathrm{mbar}, T=297.6 \mathrm{~K}$ and the volume of air in the flask was $0.578 \times 10^{-3} \mathrm{~m}^{3}$, the number of moles of the average test shows a relatively consistent value of $1.51 \mathrm{mmol}$ that is in the order of $10^{-2} \mathrm{~mol}$. The test results show the value of $R^{2}=0.9822$, meaning that the effect of temperature is strong on changes in pressure at a fixed volume.
\end{abstract}

Keywords: Thermodynamics, Charles Gay-Lussac's Law

\begin{abstract}
Abstrak: Berdasarkan kajian silabus mata kuliah termodinamika pada beberapa Program Studi Teknik di Politeknik Negeri Bandung menunjukkan kebutuhan yang sangat tinggi terhadap mata kuliah Fisika Terapan pokok bahasan Termodinamika sebagai mata kuliah prasyarat. Untuk dapat memahami konsep termodinamika melalui kegiatan praktikum, pada penelitian ini dilakukan desain dan optimasi alat percobaan Hukum Charles Gay-Lussac, hasil pengukuran dikonfirmasi dengan data perhitungan menggunakan literatur. Hukum Charles menyatakan bahwa pada tekanan tetap, volume gas ideal bermassa tertentu berbanding lurus terhadap temperaturnya dan Hukum Gay-Lussac menyatakan jika gas dalam wadah tertutup volumenya dijaga konstan maka tekanan gas berbanding lurus dengan temperatur mutlaknya. Hasil perancangan alat percobaan hukum Charles, pada $\mathrm{P}_{\text {Ukur }}=925 \mathrm{mbar}$ dan $\mathrm{T}_{\text {Ruang rata-rata }}=298 \mathrm{~K}$, diperoleh tekanan rata-rata hasil uji coba $1043 \mathrm{mbar}$. Hasil pengujian dari setting alat tersebut menunjukkan nilai koefisien determinasi rata-rata $\left(\mathrm{R}^{2}\right)=0.9969$, artinya kuatnya pengaruh suhu terhadap perubahan volume pada tekanan tetap. Pada perancangan alat percobaan hukum Gay-Lussac, pada $\mathrm{P}_{\text {Ukur }} 925$ mbar, $\mathrm{T}_{\text {Ruang rata-rata }} 297.6 \mathrm{~K}$ dan volume udara dalam labu $0.578 \mathrm{x}$ $10^{-3} \mathrm{~m}^{3}$, diperoleh jumlah mol rata-rata pengujian $1.51 \mathrm{mmol}$. Hasil pengujian menunjukkan nilai $\mathrm{R}^{2}=$ 0.9822 , artinya kuatnya pengaruh suhu terhadap perubahan tekanan pada volume tetap.
\end{abstract}

Kata Kunci: Termodinamika, Hukum Charles Gay-Lussac

\section{PENDAHULUAN}

Mata Kuliah Fisika Terapan di Politeknik Negeri Bandung merupakan pendukung mata kuliah yang ada di jurusan sehingga capaian pembelajaran harus mendukung kompetensi 
lulusan yang diharapkan jurusan. Termodinamika merupakan salah satu pokok bahasan dalam mata kuliah fisika terapan dan merupakan salah satu materi penting dalam ilmu rekayasa. Di dunia industri, banyak ditemukan cara kerja peralatan teknik yang dilandasi oleh penerapan konsep termodinamika.

Konsep termodinamika selain dipelajari dalam kelas teori juga perlu diperdalam penguasaannya melalui kegiatan praktikum di laboratorium. Dalam pembelajaran konsepkonsep fisika akan lebih mudah dikuasai jika disertakan kegiatan tambahan berupa eksperimen. Menurut Septi Budi Sartika (2012), praktikum adalah cara penyajian pelajaran, dimana peserta didik melakukan percobaan dengan mengalami dan membuktikan sendiri sesuatu yang dipelajari. Kegiatan Praktikum di Laboratorium Fisika Terapan Polban bertujuan meningkatkan pemahaman konsep fisika melalui peningkatan keterampilan generik sains mahasiswa yang dapat digunakan sebagai pendukung mata kuliah jurusan yang dilayani. Untuk peningkatan kegiatan praktikum diperlukan pengembangan alat yang telah tersedia di Laboratorium Fisika Politeknik Negeri Bandung atau pembuatan alat baru yang lebih bervariasi dalam mengeksplor besaran-besaran fisika yang diukur. Kegiatan praktikum dalam pembelajaran fisika dapat dijadikan salah satu alternatif pemecahan masalah bagi rendahnya penguasaan konsep yang dihadapi mahasiswa.

Dalam termodinamika Hukum Charles adalah hukum gas ideal yang menyatakan bahwa pada tekanan tetap, volume gas ideal bermassa tertentu berbanding lurus terhadap temperaturnya. Secara matematis, hukum Charles oleh Tipler (2005) ditulis sebagai berikut:

$\frac{V}{T}=C$ atau $\frac{V_{1}}{T_{1}}=\frac{V_{2}}{T_{2}}$

dengan

$V$ adalah volume gas $\left(\mathrm{m}^{3}\right)$,

$T$ adalah temperatur gas $(\mathrm{K})$

Persamaan (1) dapat digambarkan dengan grafik seperti pada gambar 1.

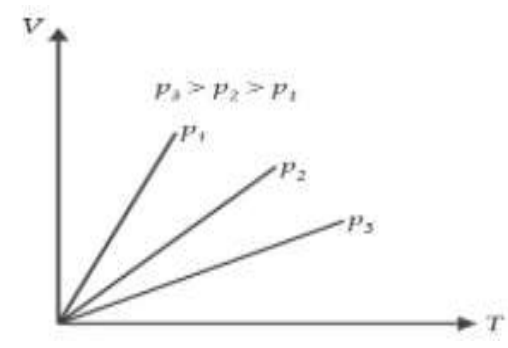

Gambar 1. Grafik Hubungan Volome (V) dan Suhu(T) pada Tekanan (P) Tetap

(Sumber: Serway, R.A. dkk, Fisika Untuk Sains dan Teknik, 2009)

Sedangkan Hukum Gay-Lussac menyebutkan bahwa: "Jika gas dalam wadah tertutup volumenya dijaga konstan maka tekanan gas berbanding lurus dengan temperatur mutlaknya". Semakin tinggi suhu saat dipanaskan maka semakin besar pula tekanan gas. Secara matematis, hukum Gay-Lussac oleh Tipler (2005) ditulis sebagai berikut: 
$\frac{P}{T}=C$ atau $\frac{P_{1}}{T_{1}}=\frac{P_{2}}{T_{2}}$

dengan

$\mathrm{P}=$ Tekanan $\left(\mathrm{N} / \mathrm{m}^{2}\right.$, Pascal $)$

$\mathrm{T}=$ suhu akhir $(\mathrm{K})$

Persamaan (2) dapat digambarkan dengan grafik seperti pada gambar 2.

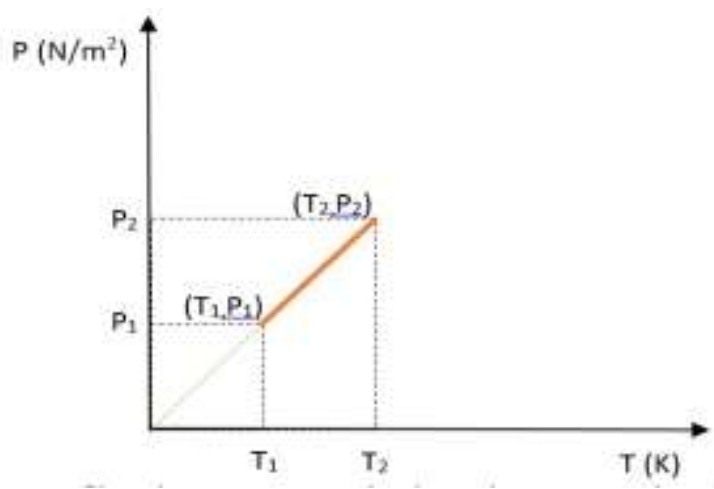

Gambar 2. Grafik Hubungan Tekanan (P) dan Suhu (T) pada Volume (V) Tetap

(Sumber: Serway, R.A. dkk, Fisika Untuk Sains dan Teknik, 2009)

\section{METODE PENELITIAN}

Penelitian ini menggunakan metode eksperimental dan dilaksanakan di Laboratorium Fisika Terapan UP MKU Politeknik Negeri Bandung. Desain alat percobaan Hukum Charles Gay-Lussac menggunakan prinsip pengukuran besaran makroskopik yang terkandung dalam persamaan Hukum Charles Gay-Lussac. Langkah penelitian terbagi ke dalam dua tahapan. Tahap pertama merancang alat percobaan hukum Charles dan gay-Lussac. Berikut adalah uraian rancangan alat percobaan:

\subsection{Rancangan alat percobaan hukum Charles}

Pada bejana berisi air yang dapat didinginkan atau dipanaskan (suhu T sebagai variabel bebas) ditempatkan tabung kaca berisi gas dengan volume V. Pada ujung bagian atas permukaan gas diisi cairan raksa agar pergerakan gas dapat diamati. Posisi pipa kapiler diatur sedemikian rupa agar stabil berdiri di dalam bejana. Ujung mulut pipa kapiler dibiarkan terbuka agar memperoleh tekanan $\mathbf{P}$ ruang yang nilainya dapat dipertahankan tetap.

\subsection{Rancangan alat percobaan hukum Gay-Lussac}

Pada bejana berisi air yang dapat didinginkan atau dipanaskan (suhu $\mathbf{T}$ sebagai variabel bebas) ditempatkan labu kaca berisi gas dengan volume $\mathbf{V}$ yang dipertahankan tetap. Posisi labu diatur sedemikian rupa agar stabil berdiri di dalam bejana. Pada ujung mulut labu dihubungkan dengan alat pengukur tekanan P. Dengan desain alat seperti ini diharapkan nilai tekanan terukur sebanding dengan suhu mutlak dari hasil pemanasan bejana sesuai dengan hukum Gay-Lussac.

Tahap kedua adalah pengujian alat percobaan Hukum Charles Gay-Lussac. Pengujian dilakukan untuk mengoptimasi hasil pengukuran dengan menggunakan alat percobaan yang 
telah didesain. Data hasil pengukuran dikonfirmasi dengan data perhitungan menggunakan literatur. Pengukuran dilakukan secara berulang untuk mengatasi ketidakpastian hasil pengukuran.

\section{HASIL DAN PEMBAHASAN}

\subsection{Perancangan Alat Percobaan Hukum Charles}

Alat percobaan Hukum Charles dirancang sesuai dengan rancangan alat yang telah diuraikan. Gambar 3 menunjukkan hasil perancangan alat percobaan Hukum Charles di Laboratorium Fisika Terapan.

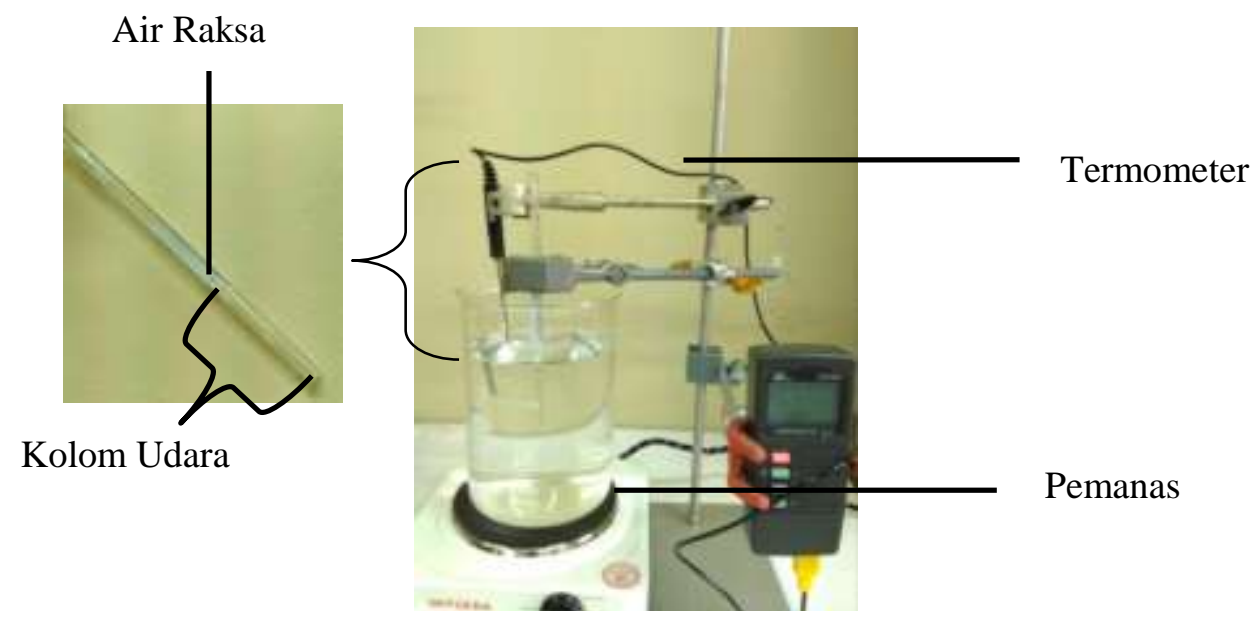

Gambar 3. Rancangan Alat Percobaan Hukum Charles

Untuk perancangan alat percobaan hukum Charles, hasil Optimasi ukuran pipa kapiler pada tekanan udara luar $\mathrm{P}_{\text {Ukur }}=925$ mbar, Suhu Ruangan $\mathrm{T}_{\text {Ruang rata-rata }}=298 \mathrm{~K}$, diuraikan pada tabel 1 berikut:

Tabel 1. Hasil Optimasi Ukuran Pipa Kapiler

\begin{tabular}{cc}
\hline Dimensi Pipa Kapiler & Ukuran \\
\hline Panjang pipa & $0.215 \mathrm{~m}$ \\
Diameter dalam & $1.95 \mathrm{~mm}$ \\
Panjang kolom udara awal $\left(\mathrm{L}_{0}\right)$ & $0.071 \mathrm{~m}$ \\
Volume Kolom Udara Awal $\left(\mathrm{V}_{0}\right)$ & $2.12 \times 10^{-7} \mathrm{~m}^{3}$ \\
Jumlah mol udara pada kolom $\left(\mathrm{n}=\frac{P_{\text {ukur }} V_{0}}{R_{\text {ruang }}}\right)$ & $0.0079 \mathrm{mmol}$ \\
\hline
\end{tabular}

Hasil pengujian dengan tiga kali pengulangan bila diplot ke dalam grafik dengan volume (sumbu y) sebagai fungsi suhu (sumbu $\mathrm{x}$ ) diperoleh koefisien determinasi $\left(\mathrm{R}^{2}\right)$ masing-masing $=0.9953,0.9984$, dan 0.997. Hasil pengujian ditunjukkan gambar 4 berikut: 

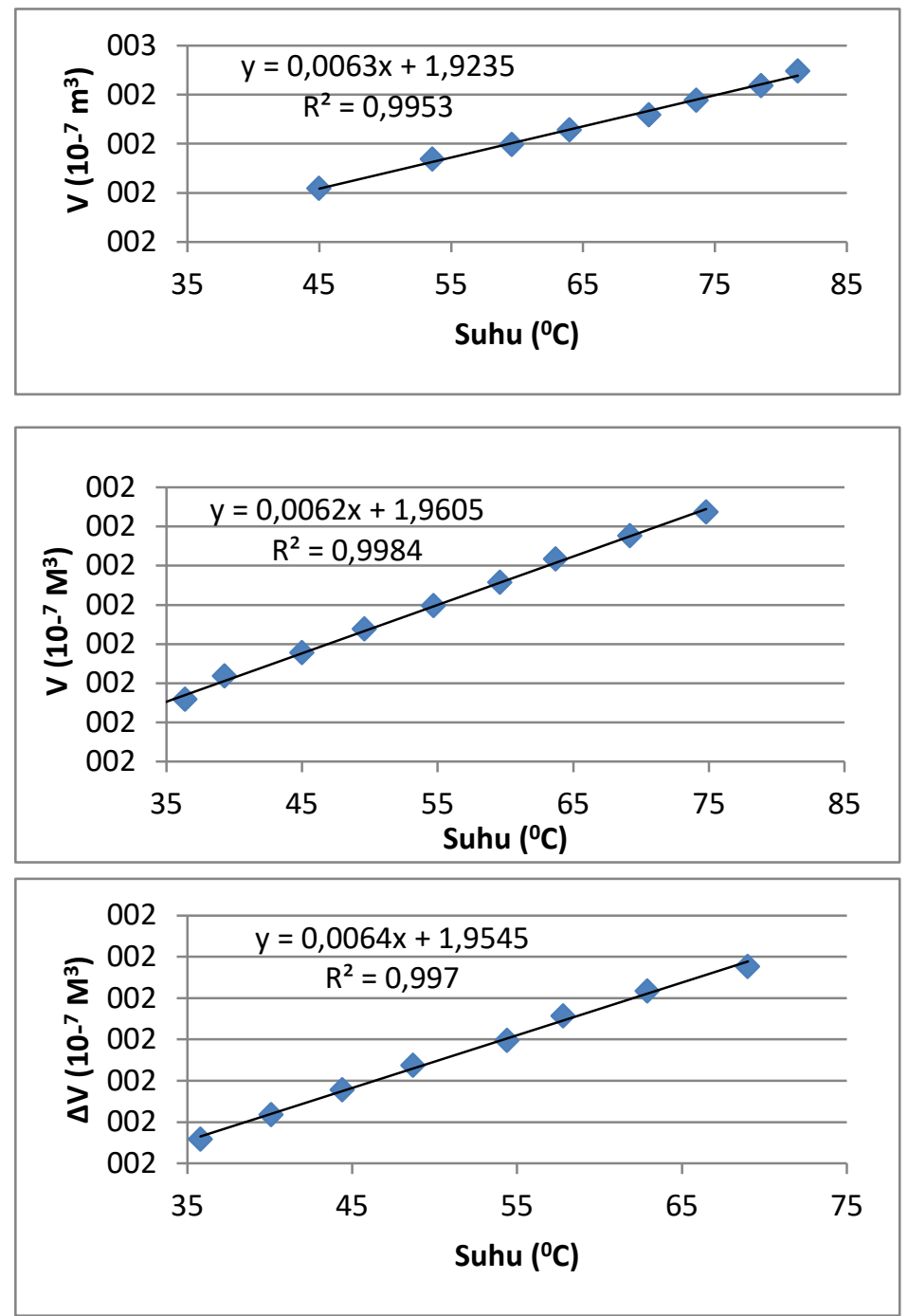

Gambar 4. Grafik Tiga Kali Pengujian Volume Kolom Udara V Terhadap Kenaikan

\section{Suhu T}

Hasil pengujian dari setting alat Percobaan Hukum Charles menunjukkan nilai koefisien determinasi rata-rata $\left(\mathrm{R}^{2}\right)=0.9969$. Menurut Raharjo (2017), nilai $\mathrm{R}^{2}$ dapat dipakai untuk memprediksi seberapa besar pengaruh variabel bebas terhadap variabel terikat. Hal ini menunjukkan perbandingan lurus antara suhu dan volumenya, serta kuatnya pengaruh suhu terhadap perubahan volume pada tekanan tetap.

Apabila persamaan linier dari hasil pengujian didekati dengan menggunakan metode Regresi Linier, yaitu salah satu metode pendekatan bagaimana dua buah variabel atau lebih itu berhubungan atau dapat diramalkan (Suratmi, 2013), maka didapat garis lurus terbaik dengan persaman $V=(0.0063 T+1.9235) \times 10^{-7} \mathrm{~m}^{3}$, nilai gradien $\mathrm{B}=0.0063 \times 10^{-7} \mathrm{~m}^{3} / \mathrm{K}$. Dari persamaan tersebut maka dapat dihitung tekanan udara luar melalui percobaan $\left(\mathrm{P}_{\text {coba }}\right)$ dengan $\mathrm{n}$ sebagai hasil hitung pada tabel 1 dan $\mathrm{R}$ adalah konstanta gas ideal : 


$$
\boldsymbol{P}_{\text {coba }}=\frac{n R}{B}=\frac{(0.0079 \mathrm{mmol})\left(8.314472 \frac{\mathrm{Joule}}{\mathrm{mol} \mathrm{K}}\right)}{\left(0.0063 \times \frac{10^{-7} \mathrm{~m}^{3}}{K}\right)}=103924 \mathrm{~Pa}=1039 \mathrm{mbar}
$$

Hasil pengujian dapat dihitung ketidakpastian relatif nya (Sardjito, 1996) dengan perumusan sebagai berikut :

$$
K S R=\left|\frac{P_{\text {coba }}-P_{u k u r}}{P_{u k u r}}\right| x 100 \% \approx 12.35 \%
$$

Perhitungan dengan cara yang sama untuk data pengujian kedua dan selanjutnya seperti ditunjukkan tabel 2 berikut:

Tabel 2. Hasil Percobaan Hukum Charles

\begin{tabular}{ccccc}
\hline $\begin{array}{c}\text { Percobaan } \\
\text { Ke - }\end{array}$ & $\begin{array}{c}\mathbf{P}_{\text {ukur }} \\
(\mathbf{m b a r})\end{array}$ & Persamaan Linier & $\begin{array}{c}\mathbf{P}_{\text {coba }} \\
(\mathbf{m b a r})\end{array}$ & $\begin{array}{c}\text { Ketidakpastian } \\
\text { Relatif }(\boldsymbol{\%})\end{array}$ \\
\hline 1 & 925 & $V=(0.0063 T+1.9235) \times 10^{-7} \mathrm{~m}^{3}$ & 1039 & 12.35 \\
2 & 925 & $V=(0.0062 T+1.9605) \times 10^{-7} \mathrm{~m}^{3}$ & 1059 & 14.51 \\
3 & 925 & $V=(0.0064 T+1.9605) \times 10^{-7} \mathrm{~m}^{3}$ & 1031 & 11.42 \\
\hline
\end{tabular}

Ketidakpastian relatif antara $\boldsymbol{P}_{\boldsymbol{c o b} \boldsymbol{a}}$ dan $\boldsymbol{P}_{\boldsymbol{u k u r}}$ menunjukkan nilai yang relatif kecil. Semakin kecil nilai KSR semakin teliti hasil pengukuran. Perbedaan yang terjadi dapat dipengaruhi oleh beberapa faktor, diantaranya: pengukuran suhu tidak diukur langsung di dalam pipa kapiler sehingga panas yang terukur tidak benar-benar sama dengan yang terjadi dalam pipa kapiler.

\subsection{Perancangan Alat Percobaan Hukum Gay-Lussac}

Alat percobaan Hukum Gay-Lussac dirancang sesuai dengan rancangan alat yang telah diuraikan. Gambar 5 menunjukkan hasil perancangan alat percobaan Hukum Gay-Lussac di Laboratorium Fisika Terapan.

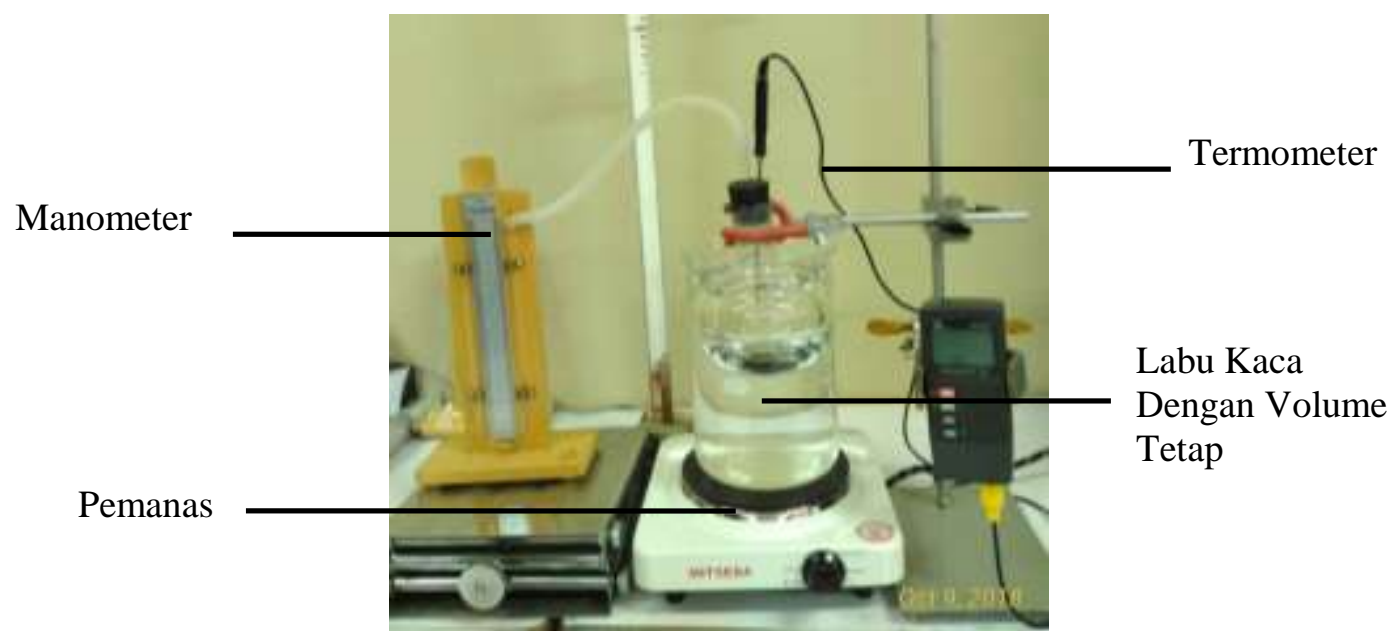

Gambar 5. Rancangan Alat Percobaan Hukum Gay-Lussac

Untuk perancangan alat percobaan hukum Gay-Lussac, data ruang percobaan dan volume labu yang digunakan ditunjukkan tabel 3 berikut: 
Tabel 3. Data Ruang Percobaan dan Volume Labu yang Digunakan

\begin{tabular}{cc}
\hline Data Percobaan & Ukuran \\
\hline Tekanan Udara Luar $\left(\mathrm{P}_{\text {Ukur }}\right)$ & $925 \mathrm{mbar}$ \\
Suhu Ruangan Rata-rata $\left(\mathrm{T}_{\text {Ruang }}\right)$ & $24.6^{0} \mathrm{C}$ \\
Volume Udara Labu $(\mathrm{V})$ & $0.578 \times 10^{-3} \mathrm{~m}^{3}$ \\
\hline
\end{tabular}

Bejana dipanaskan untuk memberi variasi suhu pada sistem dengan volume udara tetap. Pengujian alat dilakukan secara berulang untuk memperoleh hasil percobaan yang optimal. Hasil tiga kali pengujian bila diplot ke dalam grafik dengan perbedaan tekanan $\Delta \mathbf{P}$ (sumbu y) sebagai fungsi suhu (sumbu $\mathrm{x}$ ) diperoleh koefisien determinasi $\left(\mathrm{R}^{2}\right)$ masing-masing $=0.9803$, 0.9822 dan 0.9840 . Hasil pengujian ditunjukkan gambar 6 berikut:
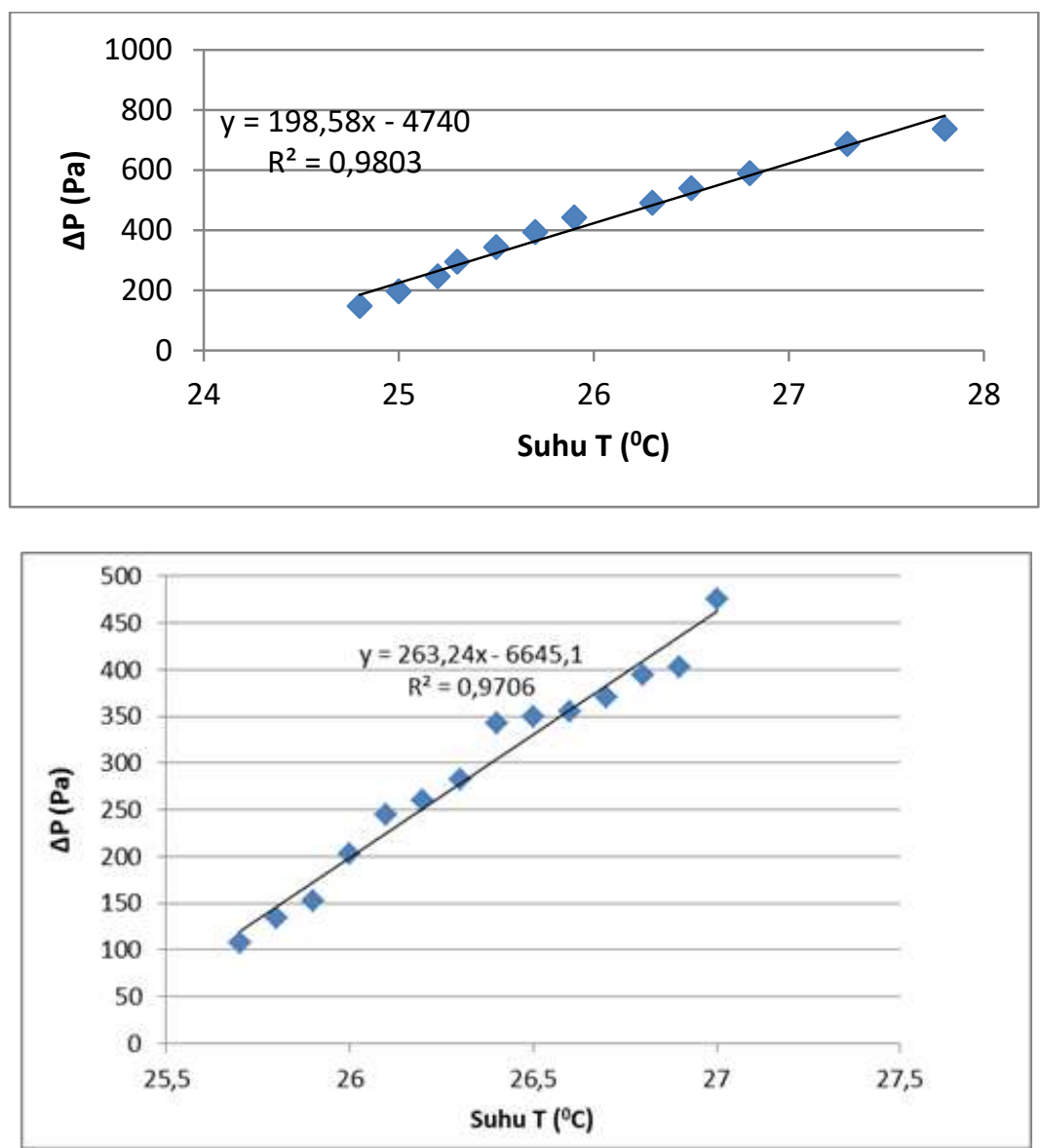


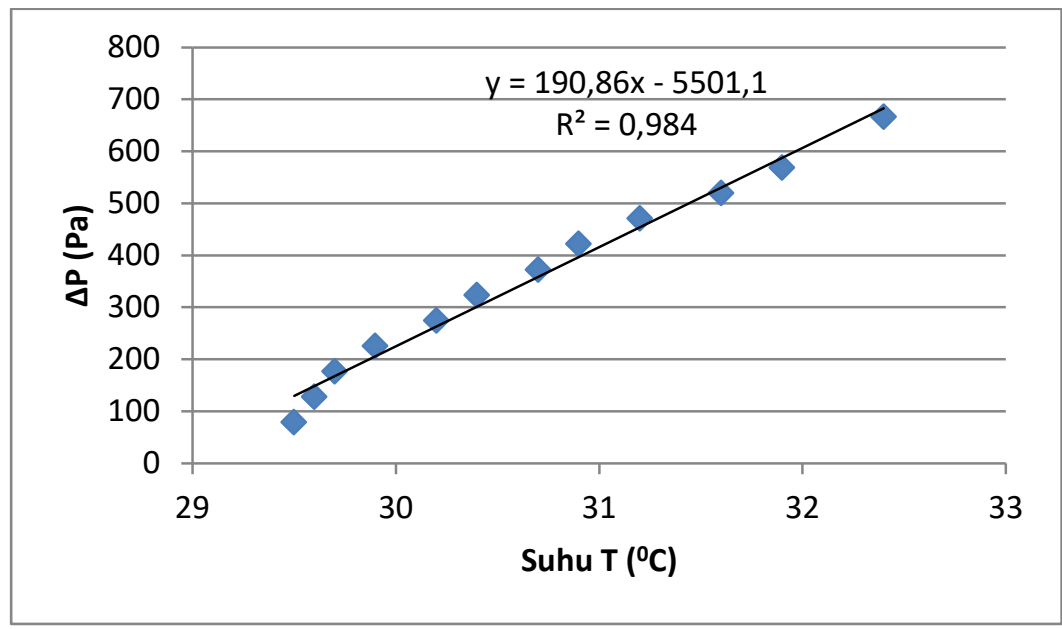

Gambar 6. Grafik Pengujian 3 Perbedaan Tekanan $\Delta \mathrm{P}$ Terhadap Kenaikan Suhu T

Hasil pengujian dari setting alat Percobaan Hukum Gay-Lussac yang diplotkan dalam grafik menunjukkan nilai koefisien determinasi rata-rata $\left(\mathrm{R}^{2}\right)=0.9822$. Hal ini menunjukkan perbandingan lurus antara suhu dan tekanan, serta kuatnya pengaruh suhu terhadap perubahan tekanan pada volume tetap.

Apabila persamaan linier dari pengujian didekati dengan menggunakan metode Regresi Linier didapat garis lurus terbaik dengan persaman $\Delta P=(198.58 T-4740) P a$, dengan gradien $\mathrm{B}=198.58 \mathrm{~Pa} / \mathrm{K}$. Dapat dihitung jumlah mol n udara pada labu:

$$
\boldsymbol{n}=\frac{V B}{R}=\frac{\left(0.578 \times 10^{-3} \mathrm{~m}^{3}\right)(198.58 \mathrm{~Pa} / \mathrm{K})}{\left(8.314472 \frac{\text { Joule }}{\text { mol K }}\right)}=\mathbf{1 3 . 8 ~} \mathbf{~ m m o l}
$$

Perhitungan dengan cara yang sama untuk data pengujian kedua dan selanjutnya seperti ditunjukkan tabel 4 berikut:

Tabel 4. Pengujian Alat Percobaan Hukum Gay Lussac

\begin{tabular}{cccc}
$\begin{array}{c}\text { Pengujian } \\
\text { Ke - }\end{array}$ & Persamaan Linier & $\begin{array}{c}\text { Mol Udara dalam } \\
\text { Labu }(\mathbf{m m o l})\end{array}$ & KSR $(\boldsymbol{\%})$ \\
\hline 1 & $\Delta P=(198.58 T-4740) P a$ & 13.8 & 31 \\
2 & $\Delta P=(263.2 T-6645.1) P a$ & 18.3 & 8.5 \\
3 & $\Delta P=(190.86 T-5501) P a$ & 13.3 & 33.5 \\
\hline
\end{tabular}

Hasil perhitungan jumlah mol pada setiap pengujian menunjukkan nilai yang relatif konsisten yaitu pada kisaran orde $10^{-2}$ mol dengan nilai KSR rata-rata $24.3 \%$.

\section{KESIMPULAN}

Hasil optimasi alat percobaan hukum Charles, pada $\mathrm{P}_{\text {Ukur }}=925 \mathrm{mbar}$ dan $\mathrm{T}_{\text {Ruang rata-rata }}=$ 298 K, diperoleh tekanan rata-rata hasil uji coba 1043 mbar. Nilai KSR rata-rata 6.89\%. Hasil pengujian dari setting alat tersebut menunjukkan nilai koefisien determinasi rata-rata $\left(\mathrm{R}^{2}\right)=$ 0.9969 , artinya kuatnya pengaruh suhu terhadap perubahan volume pada tekanan tetap. Pada perancangan alat percobaan hukum Gay-Lussac, pada $\mathrm{P}_{\text {Ukur }} 925$ mbar, $\mathrm{T}_{\text {Ruang rata-rata }} 297.6 \mathrm{~K}$ dan volume udara dalam labu $0.578 \times 10^{-3} \mathrm{~m}^{3}$, diperoleh jumlah mol rata-rata pengujian 
menunjukkan nilai yang relatif konsisten 1.51 mmol dengan nilai KSR rata-rata $24.3 \%$. Hasil pengujian menunjukkan nilai $\mathrm{R}^{2}=0.9822$, artinya kuatnya pengaruh suhu terhadap perubahan tekanan pada volume tetap.

\section{SARAN}

Berikut adalah penelitian lanjutan yang dapat dilakukan sebagai future work baik untuk penyempurnaan alat percobaan Hukum Charles Gay-Lussac maupun untuk tahap pengembangan selanjutnya:

1. Untuk memperoleh hasil pengukuran tekanan yang lebih akurat dengan nilai KSR yang lebih rendah perlu dilakukan penelitian lebih lanjut terkait dengan pengukuran suhu pada pipa kapiler.

2. Perlu dilakukan variasi nilai tekanan tetap pada percobaan Hukum Charles.

\section{DAFTAR PUSTAKA}

Raharjo, S. (2017). Makna Koefisien Determinasi (R Square). www.spssindonesia.com. Diunduh pada tanggal 1 November 2018.

Sardjito. (1996). Petunjuk Praktikum Fisika Dasar Untuk mahasiswa Politeknik, Pusat pengembangan Pendidikan Politeknik Dirjen Dikti Depdikbud.

Septi, Budi Sartika. (2012) Pengaruh Penerapan Metode Eksperimen sebagai Implementasi Kurikulum Tingkat Satuan Pendidikan (KTSP) terhadap Prestasi Belajar Siswa Pedagogi: Jurnal Pendidikan Vol. 1, No. 2 Juni 2012: 189-21.

Serway, R.A. dan Jewett, John W. (2009). Fisika Untuk Sains dan Teknik. Jakarta, Indonesia: Salemba Teknika.

Suratmi, dkk. (2013). Pengembangan Prosedur Operasi Baku (Standard Operational Prosedure) dan Modul Praktikum Fisika Terapan Berorientasi pada Kurikulum Politeknik Berbasis Kompetensi: Jurnal Sigma-Mu UP MKU POLBAN Vol. 5 No. 1 Maret 2013: Hal 34-49.

Tipler, Paul A. (2005). Fisika untuk Sains dan Teknik. Jakarta, Indonesia: Erlangga. 